\title{
Effects of endomorphin-1 postconditioning on myocardial ischemia/reperfusion injury and myocardial cell apoptosis in a rat model
}

\author{
WEI-PING ZHANG $^{1 *}$, QIAO-FENG ZONG ${ }^{1 *}$, QIN GAO $^{1}$, YING YU $^{1}$, \\ XIAO-YU GU ${ }^{1}$, YA WANG ${ }^{1}$, ZHENG-HONG $\mathrm{LI}^{1}$ and $\mathrm{MIN} \mathrm{GE}^{2}$ \\ Departments of ${ }^{1}$ Physiology and ${ }^{2}$ Pharmacology, Bengbu Medical College, Bengbu, Anhui 233030, P.R. China
}

Received July 19, 2015; Accepted July 29, 2016

DOI: $10.3892 / \mathrm{mmr} .2016 .5695$

\begin{abstract}
Endomorphins (EMs) have important roles in the body with regards to analgesia, feeding behavior, gastrointestinal movement and inflammatory reaction. Recent studies have reported that EMs may also participate in chronic hypoxia in the protection of rat myocardial ischemia/reperfusion; however, the mediator and underlying mechanisms remain to be elucidated. The aim of the present study was to investigate the effects of EM-1 postconditioning on myocardial ischemia/reperfusion injury (MIRI) and myocardial cell apoptosis in a rat model, and to assess its likely mechanisms. A total of 48 male Sprague Dawley rats were randomly divided into four groups: Sham group, ischemia/reperfusion group (IR group), ischemic postconditioning group (IPO group) and EM-1 postconditioning group (EM50 group). A MIRI model was established via occlusion of the left anterior descending branch of the coronary artery for $30 \mathrm{~min}$, followed by reperfusion for 120 min in vivo. Hemodynamic indexes were recorded and analyzed. Following reperfusion, plasma lactate dehydrogenase (LDH), creatine kinase-MB (CK-MB), malondialdehyde (MDA), superoxide dismutase (SOD), interleukin-6 (IL-6) and tumor necrosis factor- $\alpha$ (TNF- $\alpha$ ) contents or activities were measured, infarct size was determined, and the expression levels of B-cell lymphoma 2 (Bcl-2) and Bcl-2-associated $\mathrm{X}$ protein (Bax) mRNA and cleaved caspase- 3 protein were assessed. In the IR group, mean arterial pressure (MAP) and
\end{abstract}

Correspondence to: Professor Zheng-Hong Li, Department of Physiology, Bengbu Medical College, 2600 Dong Hai Avenue, Bengbu, Anhui 233030, P.R. China

E-mail: lizhbbmc@163.com

Dr Min Ge, Department of Pharmacology, Bengbu Medical College, 2600 Dong Hai Avenue, Bengbu, Anhui 233030, P.R. China E-mail: geminbbmc@163.com

*Contributed equally

Key words: endomorphin-1, myocardial ischemia/reperfusion injury, apoptosis, ischemic postconditioning, rat heart rate (HR) were decreased compared with in the sham group. In addition, $\mathrm{LDH}$ and CK-MB levels were increased; IL-6, TNF- $\alpha$ and MDA content was increased; SOD activity was decreased; the $\mathrm{Bcl}-2 / \mathrm{Bax}$ ratio was decreased; and cleaved caspase-3 protein expression levels were increased in the IR group. Compared with in the IR group, in the IPO and EM50 groups, MAP and heart rate (HR) were recovered to various extents post-reperfusion; LDH and CK-MB levels were decreased; IL-6, TNF- $\alpha$ and MDA content was decreased; SOD activity was increased; infarct size was reduced; the Bcl-2/Bax ratio was increased; and cleaved caspase-3 protein expression levels were decreased. In conclusion, EM-1 postconditioning was revealed to reduce I/R injury and inhibit myocardial cell apoptosis, which may be associated with reductions in oxidative stress and inflammatory reactions.

\section{Introduction}

Endomorphins (EMs) are a type of opioid peptide, which were initially identified in 1997 by Zadina et al (1); their identification prompted research into endogenous opioid peptides. EMs have important roles in the body with regards to analgesia (2), feeding behavior (3), gastrointestinal movement (4) and inflammation (5). In recent years, EMs have been reported to have an important role in cardiovascular biology (6), and have been shown to protect endothelial cells by slowing down the process of apoptosis and promoting proliferation under physiological concentrations $(7,8)$.

In recent years, the incidence of acute myocardial infarction has increased, and myocardial ischemia/reperfusion injury (MIRI) is considered a complex problem. Due to the time limit of ischemic preconditioning (IPC) and the invasive operation associated with ischemic postconditioning (IPO), pharmacological postconditioning (9) is considered a more feasible measure to reduce MIRI. Previous studies have suggested that exogenous opioids, including morphine, fentanyl and remifentanil, can resist MIRI and exert myocardial protection; however, the long-standing or excessive use of exogenous drugs may produce toxicity to the organism $(10,11)$. Therefore, the use of EMs, which are endogenous opioids, may be considered a promising novel therapeutic strategy. Numerous studies have confirmed that MIRI can induce oxidative stress, mito- 
chondrial dysfunction and inflammation $(12,13)$. Furthermore, previous studies have reported that EMs have an important role in clearing oxygen free radicals (14) and inhibiting mitochondrial dysfunction (15). It has also been demonstrated that EMs may participate in chronic hypoxia in the protection of rat MIRI (16). There are two types of EM: EM-1 and EM-2. EM-1 is widely distributed in the brain (17) and may have a certain correlation with cardiovascular regulatory function.

Cell apoptosis has a substantial role in MIRI; it is an important process in the occurrence and development of MIRI (18), and a relevant mechanism underlying myocardial damage and myocardial cell loss (19-21). Therefore, the present study aimed to determine the effects of EM-1 postconditioning on MIRI and myocardial cell apoptosis in a rat model, and to analyze the underlying mechanisms.

\section{Materials and methods}

Animals. Male clean-grade Sprague Dawley rats (weight, 250-350 g; age, 3 months) were obtained from the Animal Center of Bengbu Medical College (Bengbu, China). The rats were fed a normal diet and had ad libitum access to water. All rats were housed in cages at $25 \pm 1^{\circ} \mathrm{C}$ with a fixed 12-h light/dark cycle. All animal procedures were conducted in accordance with the United States National Institutes of Health Guide, and were approved by the Animal Use and Care Committee of Bengbu Medical College.

Materials and primary reagents. EM-1 was purchased from Sigma-Aldrich (Merck Millipore, Darmstadt, Germany). Lactate dehydrogenase (LDH), malondialdehyde (MDA) and superoxide dismutase (SOD) assay kits were purchased from Nanjing Jiancheng Bioengineering Institute (Nanjing, China). The creatine kinase MB (CK-MB) isoenzyme enzyme-linked immunosorbent assay (ELISA) kit, interleukin-6 (IL-6) ELISA kit and tumor necrosis factor- $\alpha$ (TNF- $\alpha$ ) ELISA kit were purchased from Biocalvin Co., Ltd. (Jiangsu, China). cDNA (\#K1622) and polymerase chain reaction (PCR) kits were purchased from Fermentas (Thermo Fisher Scientific, Inc., Waltham, MA, USA (\#K0171). B-cell lymphoma 2 (Bcl-2), Bcl-2-associated X protein (Bax) and $\beta$-actin primers were synthesized by Sangon Biotech Co., Ltd. (Shanghai China). Mouse $\beta$-actin antibody was purchased from Santa Cruz Biotechnology, Inc. (Dallas, TX, USA).

\section{Experimental method}

MIRI rat model generation in vivo. All rats were fasted for $12 \mathrm{~h}$ and were given ad libitum access to water prior to the trial. The rats were injected with $4 \%$ chloral hydrate $(1 \mathrm{ml} / 100 \mathrm{~g})$ intraperitoneally prior to the operation. Anaesthetized rats were fixed on the operating table in a supine position. A tracheal cannula was inserted into the rats, which was connected to a breathing machine (tidal volume, 2-3 ml/100 g; respiratory rate, $70-80$ times/min). The right carotid artery of each rat was separated and an arterial cannula was inserted, which was connected to the Med-Lab system (Nanjing Medease Science and Technology Co., Ltd., Nanjing China), in order to record changes to heart rate (HR) and mean arterial pressure (MAP). The chest of each rat was sheared and an incision was made along the left sternal border, separating the pericardium and exposing the heart. Subsequently, 5-0 fine silk was threaded through the bottom of the left anterior descending coronary artery (LAD). Following LAD ligation, ST-T elevation shown in the electrocardiogram indicated the success of ischemia. The LAD was ligated for $30 \mathrm{~min}$ (ischemia) followed by $120 \mathrm{~min}$ reperfusion in vivo, following $20 \mathrm{~min}$ stabilization. The MIRI model was thus accomplished (22).

Animal experimental groups. Male Sprague Dawley rats $(\mathrm{n}=48)$ were randomly divided into four groups ( $\mathrm{n}=12 /$ group): Sham group, ischemia/reperfusion group (IR), IPO group and EM-1 postconditioning (50 $\mu \mathrm{g} / \mathrm{kg})$ group (EM50). The groups underwent the following procedures: i) Sham group, LAD ligation with no other intervention for $150 \mathrm{~min}$; ii) IR group: LAD was ligated for $30 \mathrm{~min}$ (ischemia), and was reperfused for $120 \mathrm{~min}$ in vivo; iii) IPO group, after $30 \mathrm{~min}$ ischemia, three cycles of LAD clamping for $15 \mathrm{sec}$ and declamping for $15 \mathrm{sec}$ were performed prior to reperfusion; iv) EM50 group: EM-1 (50 $\mu \mathrm{g} / \mathrm{kg}$ ) was administered intravenously following LAD ligation for $25 \mathrm{~min}$, subsequently the LAD was reperfused for $120 \mathrm{~min}$ in vivo.

Determination of hemodynamic characteristics. MAP and HR were continuously monitored and recorded using the Med-Lab hemodynamic system throughout the whole process of the experiment. Rate pressure product (RPP) was calculated using the following equation: RPP $=$ MAP $\times$ HR.

Plasma IL-6, TNF- $\alpha$ and MDA content, and LDH, CK-MB and SOD activity. Following reperfusion, arterial blood samples were collected and placed in heparinized centrifuge tubes, and were centrifuged at $1,509 \mathrm{x}$ for $20 \mathrm{~min}$ at $4^{\circ} \mathrm{C}$. The supernatant was collected and stored at $-80^{\circ} \mathrm{C}$. MDA content, and LDH and SOD activities were measured using colorimetric assays. IL- 6 and TNF- $\alpha$ content, and CK-MB activity were measured by enzyme-linked immunosorbent assay using commercially available kits according to the manufacturers' protocols.

Determination of myocardial infarct size. The rats were injected with $4 \%$ chloral hydrate $(1 \mathrm{ml} / 100 \mathrm{~g})$ intraperitoneally and sacrificed by beheading prior to heart removal. The heart was removed alongside the LAD at the end of reperfusion, and $1 \%$ Evans blue was injected into the heart through the aorta. The heart was subsequently cut into $2 \mathrm{~mm}$ sections vertical to the longitudinal axis after freezing, and the sections were dyed with $1 \%$ triphenyl tetrazolium chloride in a $37^{\circ} \mathrm{C}$ water bath for 10-15 min. Subsequently, the sections were fixed in $10 \%$ formalin buffer and were divided into various regions according to color; the blue zone is considered the non-infarcted zone, the red zone is the area at risk (AAR), and the white zone is used to determine infarct size (IS). The relative area was measured using Image-Pro Plus software 6.0 (Media Cybernetics, Inc., Rockford, MD, USA) following image acquisition. The myocardial IS was expressed as a percentage of the AAR.

Detection of Bcl-2 and Bax mRNA levels by reverse transcription (RT)-PCR. Following the operation, left anterior myocardial tissues $(0.1 \mathrm{~g})$ were collected from each group and 
Table I. Polymerase chain reaction primers for Bax, Bcl-2 and $\beta$-actin.

\begin{tabular}{llll}
\hline Gene & Primer & Sequence & Product (bp) \\
\hline Bax & Forward & 5'-GGA TCG AGC AGA GAG GAT GG-3' \\
& Reverse & 5'-TGG TGA GTG AGG CAG TGA GG-3' & 464 \\
Bcl-2 & Forward & 5'-CTG GTG GAC AAC ATC GCT CTG-3' \\
& Reverse & 5'-GGT CTG CTG ACC TCA CTT GTG-3' & 228 \\
& Forward & 5'-GAT GGT GGG TAT GGG TCA GAA GGA C-3' & 632 \\
\hline
\end{tabular}

Bcl-2, B-cell lymphoma 2; Bax, Bcl-2-associated X protein.

Table II. Hemodynamic characteristics of the rats in each group.

\begin{tabular}{|c|c|c|c|c|c|}
\hline \multirow[b]{2}{*}{ Variable } & \multirow[b]{2}{*}{ Baseline } & \multirow[b]{2}{*}{ Ischemia $30 \mathrm{~min}$} & \multicolumn{3}{|c|}{ Reperfusion } \\
\hline & & & $30 \mathrm{~min}$ & $60 \mathrm{~min}$ & $120 \mathrm{~min}$ \\
\hline \multicolumn{6}{|c|}{ HR (beats/min) } \\
\hline Sham & $399.33 \pm 23.77$ & $394.50 \pm 24.44$ & $396.83 \pm 23.46$ & $383.83 \pm 21.15$ & $367.50 \pm 28.66$ \\
\hline IR & $390.50 \pm 20.42$ & $273.83 \pm 49.14^{\mathrm{a}}$ & $299.47 \pm 48.19^{a}$ & $281.26 \pm 44.60^{\mathrm{a}}$ & $284.01 \pm 34.99^{\mathrm{a}}$ \\
\hline IPO & $412.84 \pm 28.11$ & $320.63 \pm 25.77^{a, b}$ & $345.82 \pm 25.48^{\mathrm{b}, \mathrm{c}}$ & $340.60 \pm 38.48^{\mathrm{d}}$ & $341.14 \pm 20.44^{\mathrm{d}}$ \\
\hline EM50 & $404.55 \pm 11.26$ & $347.20 \pm 22.27^{\mathrm{b}, \mathrm{d}}$ & $364.23 \pm 22.76^{\mathrm{d}}$ & $352.16 \pm 14.46^{\mathrm{d}}$ & $339.94 \pm 26.65^{\mathrm{d}}$ \\
\hline \multicolumn{6}{|c|}{ MAP (mmHg) } \\
\hline Sham & $106.14 \pm 7.23$ & $99.67 \pm 7.91$ & $94.00 \pm 6.40$ & $92.56 \pm 7.19$ & $92.67 \pm 6.89$ \\
\hline IR & $117.51 \pm 10.62$ & $55.89 \pm 21.63^{\mathrm{a}}$ & $70.85 \pm 18.04^{\mathrm{a}}$ & $66.38 \pm 15.30^{\mathrm{a}}$ & $55.83 \pm 20.98^{a}$ \\
\hline IPO & $115.29 \pm 7.68$ & $77.08 \pm 9.65^{\mathrm{b}, \mathrm{c}}$ & $88.77 \pm 7.99^{\mathrm{b}}$ & $84.70 \pm 10.19^{b}$ & $80.10 \pm 22.31^{\mathrm{b}}$ \\
\hline EM50 & $110.98 \pm 13.24$ & $93.98 \pm 22.79^{d}$ & $93.36 \pm 12.41^{\mathrm{d}}$ & $85.52 \pm 10.72^{b}$ & $75.02 \pm 14.45$ \\
\hline \multicolumn{6}{|c|}{$\mathrm{RPP}\left(\mathrm{mmHg} / \mathrm{min} / 10^{-3}\right)$} \\
\hline Sham & $42.52 \pm 5.30$ & $39.42 \pm 5.06$ & $37.39 \pm 4.30$ & $35.60 \pm 4.20$ & $34.10 \pm 4.15$ \\
\hline IR & $45.80 \pm 3.63$ & $15.79 \pm 7.93^{\mathrm{a}}$ & $20.77 \pm 4.74^{\mathrm{a}}$ & $18.73 \pm 5.64^{\mathrm{a}}$ & $16.18 \pm 7.00^{\mathrm{a}}$ \\
\hline IPO & $47.61 \pm 4.83$ & $24.88 \pm 5.02^{\mathrm{a}, \mathrm{b}}$ & $30.83 \pm 4.89^{\mathrm{d}}$ & $28.72 \pm 3.88^{\mathrm{d}}$ & $27.22 \pm 7.09^{\mathrm{d}}$ \\
\hline EM50 & $44.99 \pm 6.22$ & $32.90 \pm 9.37^{\mathrm{d}}$ & $34.20 \pm 6.42^{\mathrm{d}}$ & $30.22 \pm 4.87^{\mathrm{b}}$ & $25.66 \pm 6.13^{\mathrm{b}, \mathrm{c}}$ \\
\hline
\end{tabular}

Data are presented as the mean \pm standard deviation. ${ }^{\mathrm{a}} \mathrm{P}<0.01 \mathrm{vs}$. Sham group; ${ }^{\mathrm{b}} \mathrm{P}<0.05$ vs. IR group, ${ }^{\mathrm{c}} \mathrm{P}<0.05$ vs. Sham group, ${ }^{\mathrm{d}} \mathrm{P}<0.01 \mathrm{vs}$. IR group. Sham, left anterior descending coronary artery ligation with no other intervention; IR, ischemia/reperfusion; IPO, ischemic postconditioning; EM50, endomorphin-1 (50 $\mu \mathrm{g} / \mathrm{kg}$ ) postconditioning; MAP, mean arterial pressure; HR, heart rate; RPP, rate pressure product.

homogenized, and total RNA was extracted using TRIzol ${ }^{\circledR}$ (Invitrogen; Thermo Fisher Scientific, Inc.), according to the manufacturer's protocol. Total RNA $(2 \mu \mathrm{g})$ was reverse transcribed to cDNA in a $25 \mu 1$ PCR reaction volume, containing $1 \mu \mathrm{l}$ forward primer, $1 \mu \mathrm{l}$ reverse primer, $9 \mu 1$ nuclease-free water, $12.5 \mu \mathrm{l}$ PCR Master mix and $1.5 \mu \mathrm{l}$ cDNA (all reagents were obtained from Fermentas; Thermo Fisher Scientific, Inc.) Subsequently RNA concentration was detected, and RT and PCR amplification were conducted. The primer sequences are shown in Table I. The PCR cycling conditions were as follows: Initial denaturation at $95^{\circ} \mathrm{C}$ for $3 \mathrm{~min}$; followed by 30 cycles of denaturation at $95^{\circ} \mathrm{C}$ for $50 \mathrm{sec}$, annealing at $59.4^{\circ} \mathrm{C}(\beta$-actin), $64.5^{\circ} \mathrm{C}$ (Bax), $61.5^{\circ} \mathrm{C}(\mathrm{Bcl}-2)$ for $50 \mathrm{sec}$, and extension at $72^{\circ} \mathrm{C}$ for $60 \mathrm{sec}$; and final extension at $72^{\circ} \mathrm{C}$ for $10 \mathrm{~min}$; PCR products were then maintained at $4^{\circ} \mathrm{C}$. The PCR products were analyzed by $1 \%$ agarose gel electrophoresis and were stained with ethidium bromide. The densitometric results for Bcl-2 and Bax were compared with corresponding $\beta$-actin levels to account for loading differences. Tanon Dots 3. 1. 2 software (Tanon Science \& Technology Co., Ltd., Shanghai, China) was used for analysis.

Detection of cleaved caspase-3 protein by western blotting. Following the operation, rat ventricular tissues $(0.1 \mathrm{~g})$ were collected from each group and were homogenized in $1 \mathrm{ml}$ protein extraction buffer ( $10 \mu \mathrm{l}$ phenylmethylsulfonyl fluoride, $990 \mu 1$ lysis buffer). The supernatant was collected following centrifugation $\left(12,000 \times \mathrm{g}\right.$ for $30 \mathrm{~min}$ at $\left.4^{\circ} \mathrm{C}\right)$ and protein content was determined using the bicinchoninic acid method. The quantity of the total protein samples was $20 \mu \mathrm{g}$, which was diluted in sodium dodecyl sulfate-polyacrylamide gel electrophoresis (SDS-PAGE) loading buffer. Following denaturation, the samples were separated by $12 \%$ SDS-PAGE and were transferred to polyvinylidene difluoride membranes. The 

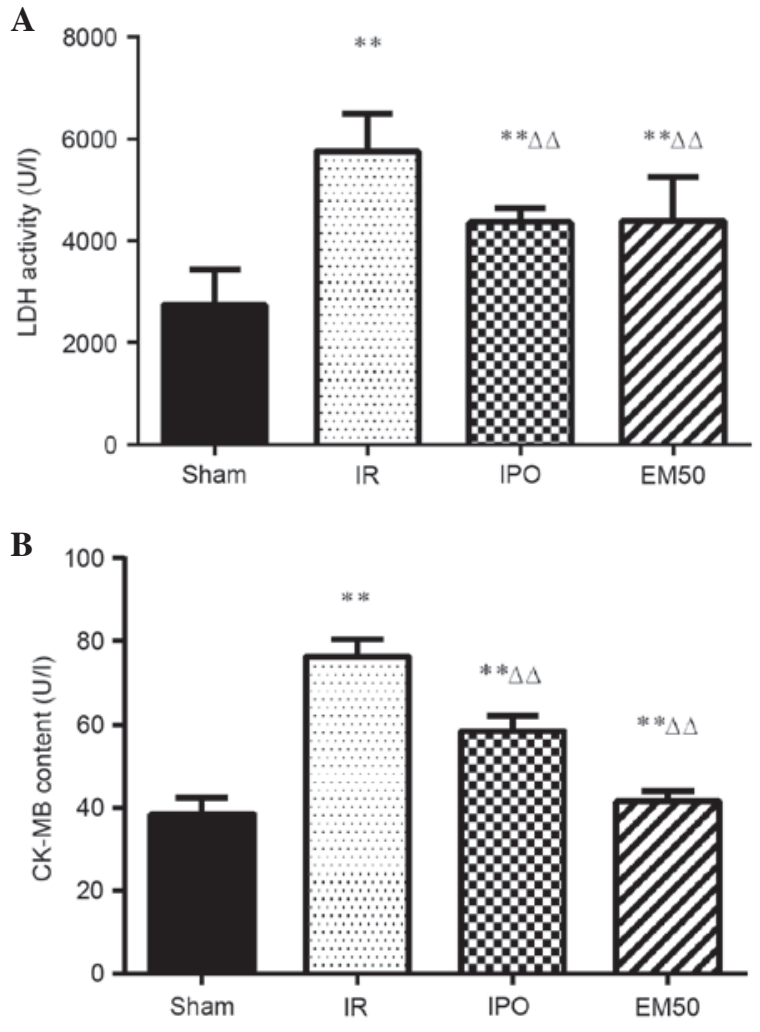

Figure 1. Effects of EM50 and IPO on (A) plasma LDH and (B) CK-MB activities in rats. Data are presented as the mean \pm standard deviation. ${ }^{* *} \mathrm{P}<0.01 \mathrm{vs}$. Sham group; ${ }^{\Delta \Delta} \mathrm{P}<0.01$ vs. IR group. Sham, left anterior descending coronary artery ligation with no other intervention; IR, ischemia/reperfusion; IPO, ischemic postconditioning; EM50, endomorphin-1 (50 $\mu \mathrm{g} / \mathrm{kg})$ postconditioning; $\mathrm{LDH}$, lactate dehydrogenase; CK-MB, creatine kinase.

membranes were blocked with $5 \%$ skimmed milk at $37^{\circ} \mathrm{C}$ for $120 \mathrm{~min}$. The membranes were then incubated at $4^{\circ} \mathrm{C}$ overnight with rabbit cleaved caspase-3 antibody (1:1,000 cat. no. \#9664) and mouse $\beta$-actin antibody (1:500; cat. no. \#BM0627). Subsequently, membranes were incubated for $60 \mathrm{~min}$ at $37^{\circ} \mathrm{C}$ with horseradish peroxidase (HRP)-conjugated anti-mouse immunoglobulin (Ig)G (1:10,000; cat. no. \#BA1050)) or HRP-conjugated anti-rabbit IgG (1:10,000; cat. no. \#BA1054) secondary antibodies. The membranes were visualized using a chemiluminescent HRP substrate. The band densities were determined and analyzed with a automatic digital gel image analysis system Tanon 3500 (Tanon Science \& Technology Co., Ltd., Shanghai, China).

Statistical analysis. Data are presented as the mean \pm standard deviation $(n=12)$. One-way analysis of variance followed by least significance difference test was used for multiple comparisons. All data were analyzed using GraphPad Prism version 4.0 software (GraphPad Software, Inc., San Diego, CA, USA). $\mathrm{P}<0.05$ was considered to indicate a statistically significant difference.

\section{Results}

Alterations to hemodynamic characteristics. Basal HR, MAP and RPP were not identified to be significantly different between the groups at baseline $(\mathrm{P}>0.05)$. During the period
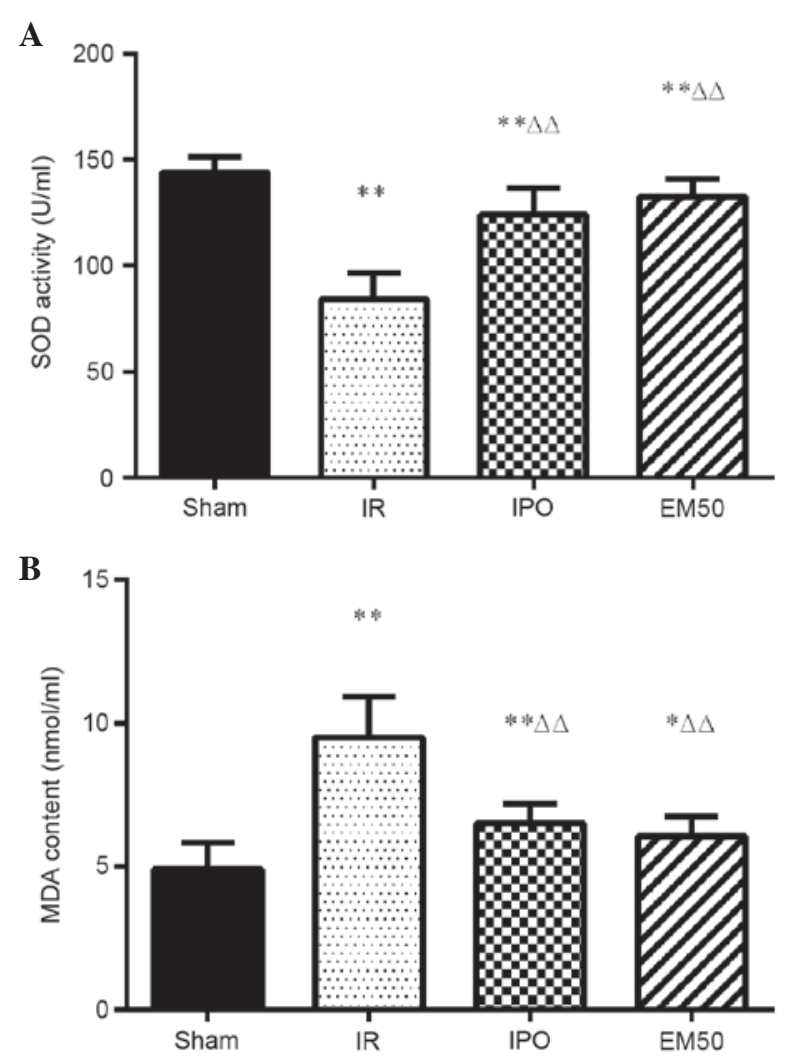

Figure 2. Effects of EM50 and IPO on the plasma activity of (A) SOD and content of (B) MDA in rats. Data are presented as the mean \pm standard deviation. ${ }^{*} \mathrm{P}<0.05,{ }^{* *} \mathrm{P}<0.01$ vs. Sham group; ${ }^{\Delta \Delta} \mathrm{P}<0.01$ vs. IR group. Sham, left anterior descending coronary artery ligation with no other intervention; IR, ischemia/reperfusion; IPO, ischemic postconditioning; EM50, endomorphin-1 $(50 \mu \mathrm{g} / \mathrm{kg})$ postconditioning; SOD, superoxide dismutase; MDA, malondialdehyde.

of ischemia, HR, MAP and RPP were significantly decreased in the IR group $(\mathrm{P}<0.01)$ compared with in the sham group. Compared with in the IR group, HR, MAP and RPP were increased in the IPO and EM50 groups $(\mathrm{P}<0.05, \mathrm{P}<0.01)$. During the period of reperfusion, HR, MAP and RPP were significantly decreased in the IR group $(\mathrm{P}<0.01)$ compared with the sham group. Compared with in the IR group, HR, MAP and RPP were increased in the IPO and EM50 groups $(\mathrm{P}<0.05, \mathrm{P}<0.01)$ (Table II).

Alterations in LDH and CK-MB plasma activities. In the IR, IPO and EM50 groups, LDH and CK-MB activities were significantly higher compared with in the sham group $(\mathrm{P}<0.01)$. Compared with in the IR group, LDH and CK-MB activities were significantly decreased in the IPO and EM50 groups (Fig. 1; $\mathrm{P}<0.01$ ).

Alterations in MDA content and SOD activity in the plasma. Compared with Sham group, in IR, IPO, and EM50 groups, SOD activity was significantly reduced and MDA content was increased. Compared with in the IR group, SOD activity was significantly increased and MDA content was significantly decreased in the IPO and EM50 groups (Fig. 2; P<0.01).

Alterations in IL-6 and TNF- $\alpha$ plasma content. In the IR group, IL- 6 and TNF- $\alpha$ levels were significantly increased 

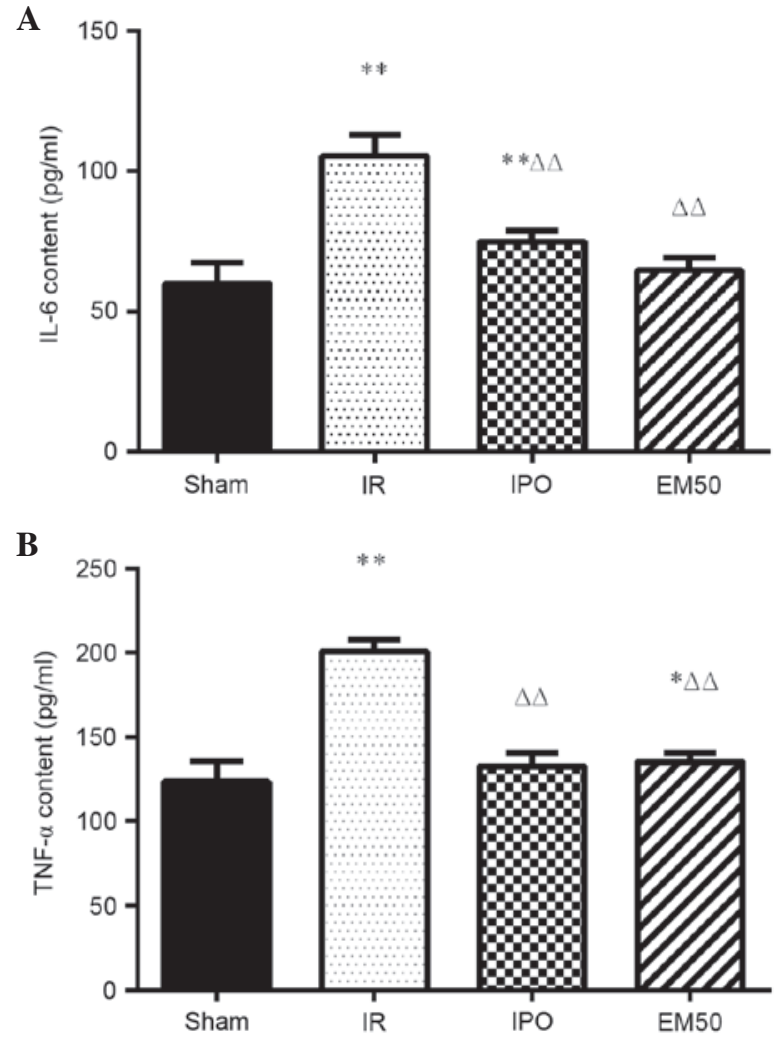

Figure 3. Effects of EM50 and IPO on the plasma contents of (A) IL-6 and (B) TNF- $\alpha$ in rats. Data are presented as the mean \pm standard deviation. ${ }^{*} \mathrm{P}<0.05$, ${ }^{* *} \mathrm{P}<0.01$ vs. Sham group; ${ }^{\Delta \Delta} \mathrm{P}<0.01$ vs. IR group. Sham, left anterior descending coronary artery ligation with no other intervention; IR, ischemia/reperfusion; IPO, ischemic postconditioning; EM50, endomorphin-1 (50 $\mu \mathrm{g} / \mathrm{kg})$ postconditioning; IL-6, interleukin-6; TNF- $\alpha$, tumor necrosis factor- $\alpha$.

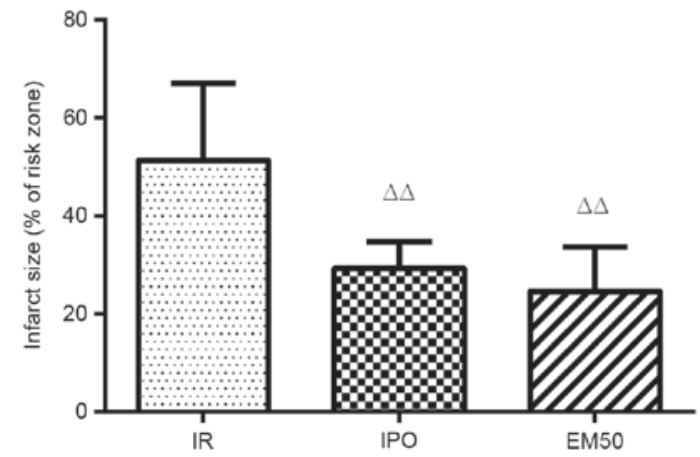

Figure 4. Effects of EM50 and IPO on rat myocardial infarct size in vivo. Data are presented as the mean \pm standard deviation. ${ }^{\Delta \Delta} \mathrm{P}<0.01$ vs. IR group IR, ischemia/reperfusion; IPO, ischemic postconditioning; EM50, endomorphin-1 $(50 \mu \mathrm{g} / \mathrm{kg})$ postconditioning.

compared with in the sham group $(\mathrm{P}<0.01)$. Compared with in the IR group, IL-6 and TNF- $\alpha$ levels were significantly decreased in the IPO and EM50 groups $(\mathrm{P}<0.01$; Fig. 3).

Alterations to myocardial infarct size in rats. Myocardial infarct size (\% IS/AAR) was significantly decreased in the IPO and EM50 groups $(\mathrm{P}<0.01)$ compared with in the IR group (Fig. 4).

Alterations in the mRNA expression levels of myocardial $B c l-2$ and Bax. The results of the RT-PCR revealed that,
A

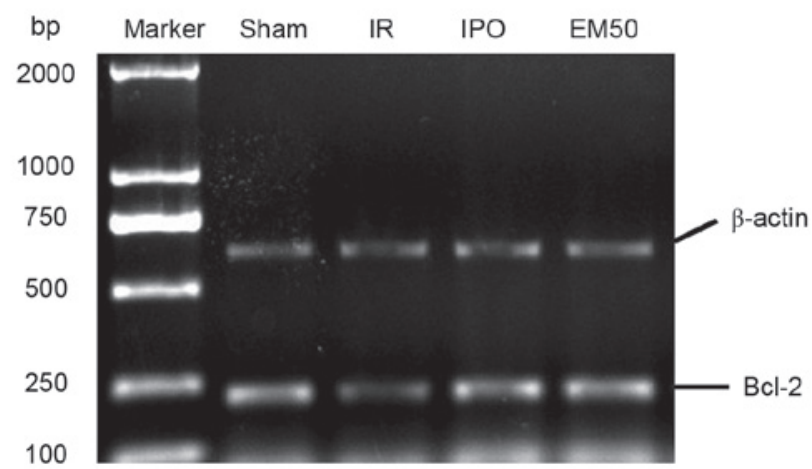

B
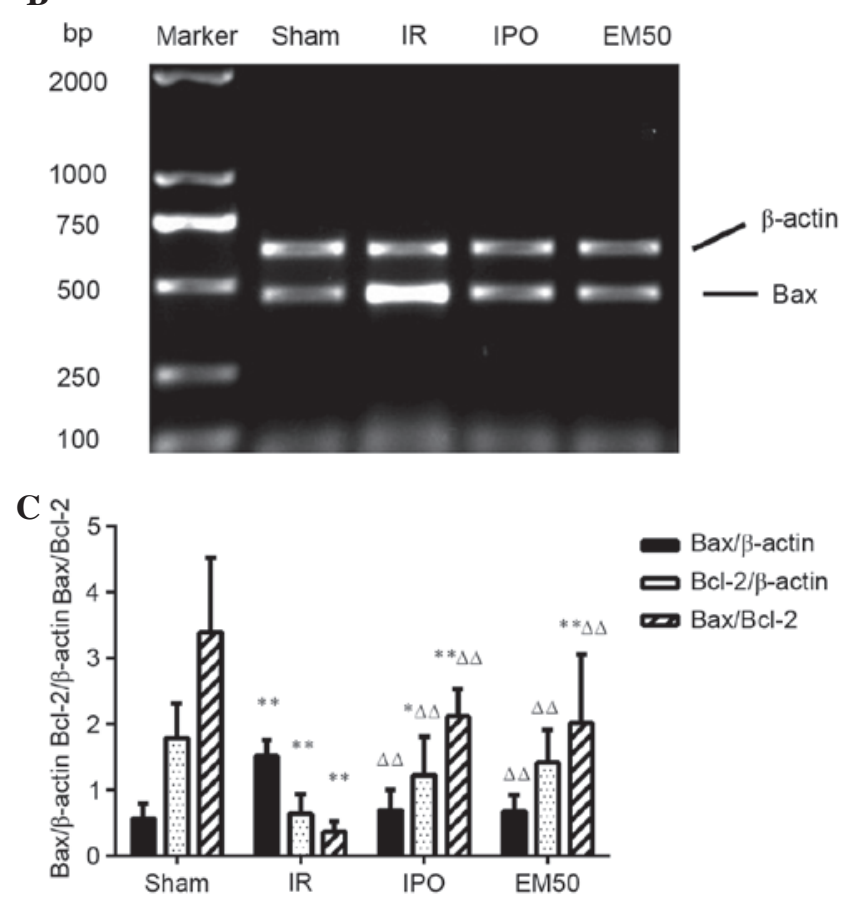

Figure 5. mRNA expression levels of (A) Bcl-2 and (B) Bax (C) Semi-quantitative analysis of Bcl-2 and Bax expression, and the $\mathrm{Bcl}-2 / \mathrm{Bax}$ ratio in rats. Data are presented as the mean \pm standard deviation. ${ }^{*} \mathrm{P}<0.05,{ }^{* *} \mathrm{P}<0.01$ vs. Sham group; ${ }^{\Delta \Delta} \mathrm{P}<0.01$ vs. IR group; Sham, left anterior descending coronary artery ligation with no other intervention; IR, ischemia/reperfusion; IPO, ischemic postconditioning; EM50, endomorphin-1 (50 $\mu \mathrm{g} / \mathrm{kg})$ postconditioning; Bcl-2, B-cell lymphoma 2; Bax, Bcl-2-associated $\mathrm{X}$ protein.

compared with the sham group, the mRNA expression levels of $\mathrm{Bcl}-2$ and the ratio of $\mathrm{Bcl}-2 / \mathrm{Bax}$ were significantly reduced $(\mathrm{P}<0.01)$, whereas the expression levels of Bax were significantly increased $(\mathrm{P}<0.01)$ in the IR group. Compared with in the IR group, the mRNA expression levels of $\mathrm{Bcl}-2$ and the ratio of $\mathrm{Bcl}-2 / \mathrm{Bax}$ were significantly increased $(\mathrm{P}<0.01)$, whereas the mRNA expression levels of Bax were significantly reduced $(\mathrm{P}<0.01)$ in the IPO and EM50 groups (Fig. 5).

Alterations in the protein expression levels of cleaved caspase-3. The protein expression levels of cleaved caspase-3 were higher in the IR, IPO and EM50 groups compared with in the sham group $(\mathrm{P}<0.05, \mathrm{P}<0.01)$. Compared with in the IR group, the ratio of cleaved caspase- $3 / \beta$-actin was significantly reduced in the IPO and EM50 groups ( $\mathrm{P}<0.01$; Fig. 6$)$. 
A
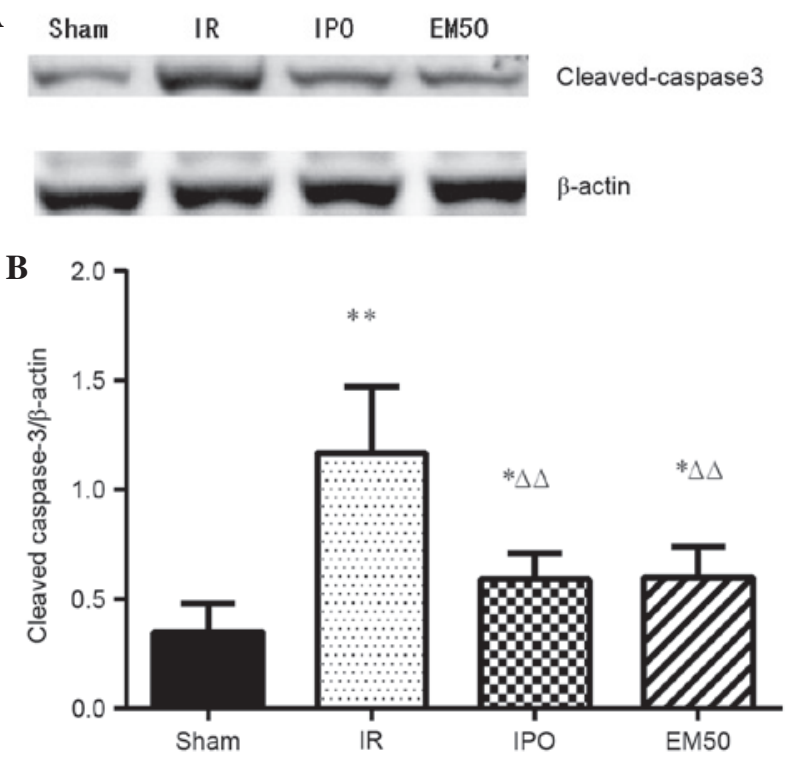

Figure 6. (A) Representative western blot and (B) semi-quantitative analysis of the cleaved caspase- $3 / \beta$-actin protein expression ratio in the myocardium of the various groups. Data are presented as the mean \pm standard deviation. ${ }^{*} \mathrm{P}<0.05,{ }^{* *} \mathrm{P}<0.01$ vs. Sham group; ${ }^{\Delta \Delta} \mathrm{P}<0.01$ vs. IR group. Sham, left anterior descending coronary artery ligation with no other intervention; IR, ischemia/reperfusion; IPO, ischemic postconditioning; EM50, endomorphin-1 $(50 \mu \mathrm{g} / \mathrm{kg})$ postconditioning.

\section{Discussion}

The myocardial restoration of blood flow following ischemia may induce significant pathological and physiological reperfusion-associated alterations to myocardial cells and the local vascular network, further aggravating myocardial damage; this process is known as MIRI. In the present study, a successful rat model of MIRI was generated in vivo. Hemodynamic indexes, myocardial enzymes and myocardial infarct size all reflect the degree of I/R damage. Previous studies have demonstrated that the primary mechanisms underlying MIRI may include excessive production of free radicals, infiltration of inflammatory cells, mitochondrial dysfunction and apoptosis of myocardial cells (19,23-25). Therefore, reducing the generation of free radicals (26), inhibiting the inflammatory response and suppressing apoptosis (27) may markedly reduce I/R injury.

The myocardial restoration of blood flow following ischemia may produce a large number of free radicals, which can cause oxidative stress, lipid peroxidation and lead to further injury of the myocardial tissue. SOD is one of the most important radical scavenging enzymes, whereas MDA is a metabolite of lipid peroxidation; therefore, measuring plasma SOD activity and MDA content can reflect the production of oxygen free radicals and the degree of myocardial cell damage (28). The results of the present study indicated that SOD activity was increased and MDA content was reduced in the plasma from IPO and EM50 groups compared with in the IR group. These results suggested that EM-1 postconditioning may alleviate MIRI by reducing the production of free radicals.

Inflammation is an important mechanism that is closely associated with the occurrence and development of MIRI (29). MIRI is characterized by a local or systemic inflammatory response, the development of which is complex. TNF- $\alpha$ is a cytokine that is predominantly produced by macrophages, which is involved in the formation and development of MIRI. It has previously been reported that excessive activation of TNF- $\alpha$ can significantly damage myocardial function and prompt myocardial cell apoptosis, thus increasing myocardial damage (30). IL-6 is considered a marker of inflammation, which is responsible for inflammatory regulation and is also closely associated with the occurrence and development of MIRI (31). The present study indicated that in the IPO and EM50 groups the plasma levels of IL-6 and TNF- $\alpha$ were reduced compared with in the IR group. These findings suggested that EM-1 postconditioning may alleviate MIRI by inhibiting the inflammatory response.

Cell apoptosis is the primary mechanism underlying MIRI. Cell apoptosis is controlled by several genes and enzymatic reactions, the molecular regulatory mechanism of which is complex. The Bcl-2 family has an important role in cell apoptosis, and the $\mathrm{Bcl}-2$ gene is the most representative anti-apoptotic gene of the Bcl-2 family. The Bax gene shares $21 \%$ amino acid sequence homology with the Bcl-2 gene, and is able to suppress the anti-apoptotic function of $\mathrm{Bcl}-2$; the $\mathrm{Bcl}-2 / \mathrm{Bax}$ ratio $(32,33)$ determines the occurrence of cell apoptosis. The cysteine aspartic acid specific protease, or caspase, family also has an important role in mediating apoptosis. Caspase-3 is an important caspase family enzyme that induces the execution of apoptosis, and is involved in the process of cell apoptosis after activation by enzyme digestion. In addition, caspase-3 is an important proteinase of the caspase enzyme cascade reaction; therefore, caspase-3 is considered an enzymatic marker of apoptosis. The present study demonstrated that in the IPO and EM50 groups the Bcl-2/Bax ratio was increased, whereas the protein expression levels of cleaved caspase- 3 were reduced compared with the IR group; therefore, EM-1 postconditioning may produce anti-apoptotic effects in MIRI.

There are several mechanisms underlying MIRI and their relationship is complex. Causal relationships may exist between the mechanisms, and they may interact with each other leading to myocardial injury. The number of neutrophils is markedly increased during reperfusion, and neutrophils produce an excess of oxygen free radicals, which can in turn induce oxidative stress, lipid peroxidation and inflammation, thus promoting cell apoptosis leading to further injury of myocardial tissue. It has previously been reported that the production of oxygen free radicals, accumulation of neutrophils and complement activation may be associated with the inflammatory response (34). Furthermore, the excessive activation of TNF- $\alpha$ can prompt myocardial cell apoptosis and increase myocardial damage (30). The present study demonstrated that EMs may produce anti-apoptotic effects by resisting oxidative stress, lipid peroxidation and inhibiting the inflammatory response; it may be hypothesized that EMs also produce an anti-apoptotic effect via certain signaling pathways, such as the phopshoinositide 3-kinase/Akt and extracellular signal-regulated kinases / 2 signaling pathways; the related mechanisms require further study.

In conclusion, the present study demonstrated that EM-1 postconditioning may exert myocardial protection and anti-apoptotic effects by resisting oxidative stress, lipid peroxidation and inhibiting the inflammatory response. 
Although EMs only have four amino acid residues, they contain abundant information. Therefore, in the future, EMs may have broad application prospects, not only in analgesia, but also in the treatment of cardiovascular conditions.

\section{Acknowledgements}

The present study was supported by research grants from the Chinese National Natural Science Foundation (grant no. 81472656) and the Anhui Province Natural Science Foundation (grant no. 1508085MH170).

\section{References}

1. Zadina JE, Hackler L, Ge LJ and Kastin AJ: A potent and selective endogenous agonist for the mu-opiate receptor. Nature 386: 499-502, 1997.

2. Mizoguchi H, Takagi H, Watanabe C, Yonezawa A, Sato T, Sakurada T and Sakurada S: Involvement of multiple $\mu$-opioid receptor subtypes on the presynaptic or postsynaptic inhibition of spinal pain transmission. Peptides 51: 15-25, 2014.

3. Brunetti L, Ferrante C, Orlando G, Recinella L, Leone S, Chiavaroli A, Di Nisio C, Shohreh R, Manippa F, Ricciuti A, et al: Orexigenic effects of endomorphin-2 (EM-2) related to decreased $\mathrm{CRH}$ gene expression and increased dopamine and norepinephrine activity in the hypothalamus. Peptides 48: 83-88, 2013.

4. Wang CL, Zhou Y, Guo C, Zhang Y and Wang R: In vivo characterization of intestinal effects of endomorphin-1 and endomorphin-2 in type 1 diabetic mice. Eur J Pharmacol 698: 499-504, 2013.

5. Block L, Björklund U, Westerlund A, Jörneberg P, Biber B and Hansson E: A new concept affecting restoration of inflammation-reactive astrocytes. Neuroscience 250: 536-545, 2013

6. Chen ZC, Shieh JP, Chung HH, Hung CH, Lin HJ and Cheng JT: Activation of peripheral opioid $\mu$-receptors in blood vesse may lower blood pressure in spontaneously hypertensive rats Pharmacology 87: 257-264, 2011.

7. Dai X, Song HJ, Cui SG, Wang T, Liu Q and Wang R: The stimulative effects of endogenous opioids on endothelial cell proliferation, migration and angiogenesis in vitro. Eur J Pharmacol 628: 42-50, 2010.

8. Liu J, Wei S, Tian L, Yan L, Guo Q and Ma X: Effects of endomorphins on human umbilical vein endothelial cells under high glucose. Peptides 32: 86-92, 2011.

9. Burley DS and Baxter GF: Pharmacological targets revealed by myocardial postconditioning. Curr Opin Pharmacol 9: 177-188, 2009.

10. Tanaka K, Kersten JR and Riess ML: Opioid-induced cardioprotection. Curr Pharm Des 20: 5696-5705, 2014.

11. Li R, Wong GT, Wong TM, Zhang Y, Xia Z and Irwin MG: Intrathecal morphine preconditioning induces cardioprotection via activation of delta, kappa, and mu opioid receptors in rats. Anesth Analg 108: 23-29, 2009.

12. Brown DA, Sabbah HN and Shaikh SR: Mitochondrial inner membrane lipids and proteins as targets for decreasing cardiac ischemia/reperfusion injury. Pharmacol Ther 140: 258-266, 2013

13. Neri M, Fineschi V, Di Paolo M, Pomara C, Riezzo I, Turillazzi E and Cerretani D: Cardiac oxidative stress and inflammatory cytokines response after myocardial infarction. Curr Vasc Pharmacol 13: 26-36, 2015

14. Gong P, Chen FX, Zhao Q, Ma GF and Wang R: The oxidation metabolites of endomorphin 1 and its fragments induced by free radicals. J Pept Sci 15: 337-344, 2009.

15. Feng Y, Lu Y, Lin X, Gao Y, Zhao Q, Li W and Wang R: Endomorphins and morphine limit anoxia-reoxygenation-induced brain mitochondrial dysfunction in the mouse. Life Sci 82 : 752-763, 2008.
16. Maslov LN, Naryzhnaia NV, Tsibulnikov SY, Kolar F, Zhang Y, Wang H, Gusakova AM and Lishmanov YB: Role of endogenous opioid peptides in the infarct size-limiting effect of adaptation to chronic continuous hypoxia. Life Sci 93: 373-379, 2013.

17. Martin-Schild S, Gerall AA, Kastin AJ and Zadina JE: Differential distribution of endomorphin 1- and endomorphin 2-like immunoreactivities in the CNS of the rodent. J Comp Neurol 405: 450-471, 1999.

18. Singh SS and Kang PM: Mechanisms and inhibitors of apoptosis in cardiovascular diseases. Curr Pharm Des 17: 1783-1793, 2011.

19. Savateev AV and Savateeva-Liubimova TN: Apoptosis-universal mechanisms of cell death and survival in ischemia and reperfusion: Ways to pharmacological control. Eksp Klin Farmakol 73: 44-49, 2010 (In Russian).

20. Eefting F, Rensing B, Wigman J, Pannekoek WJ, Liu WM, Cramer MJ, Lips DJ and Doevendans PA: Role of apoptosis in reperfusion injury. Cardiovasc Res 61: 414-426, 2004.

21. Yu-hui H, Yun F, Fen J and Xing L: Study about cardiomyocyte apoptosis in myocardial ischemic-reperfusion injury of rats and NF- $\kappa$ B p65, iNOS expression. Xi Bao Yu Fen Zi Mian Yi Xue Za Zhi 26: 868-870, 2010 (In Chinese).

22. Zhou H, Hou SZ, Luo P, Zeng B, Wang JR, Wong YF, Jiang ZH and Liu L: Ginseng protects rodent hearts from acute myocardial ischemia reperfusion injury through GR/ER-activated RISK pathway in an endothelial NOS-dependent mechanism. J Ethnopharmacol 135: 287-298, 2011.

23. Mozaffari MS, Liu JY, Abebe W and Baban B: Mechanisms of load dependency of myocardial ischemia reperfusion injury. Am J Cardiovasc Dis 3: 180-196, 2013.

24. Saleem MT, Chetty MC and Kavimani S: Putative antioxidant property of sesame oil in an oxidative stress model of myocardial injury. J Cardiovasc Dis Res 4: 177-181, 2013.

25. Gottlieb RA: Cell death pathways in acute ischemia/reperfusion injury. J Cardiovasc Pharmacol Ther 16: 233-238, 2011.

26. Kurian GA, Suryanarayanan S, Raman A and Padikkala J: Antioxidant effects of ethyl acetate extract of Desmodium gangeticum root on myocardial ischemia reperfusion injury in rat hearts. Chin Med 5: 3, 2010

27. Yi X, Cui X, Wu P, Wang S, Wang G, Yang X, Yang F, Zheng S and Li Z: Effects of N-acetylcysteine on apoptosis induced by myocardial ischemia reperfusion injury in rats' heart transplantation. Zhongguo Xiu Fu Chong Jian Wai Ke Za Zhi 27: 1234-1239, 2013 (In Chinese).

28. Gao YH, Chen L, Ma YL and He QY: Chronic intermittent hypoxia aggravates cardiomyo -cyte apoptosis in rat ovariectomized model. Chin Med J (Engl) 125: 3087-3092, 2012.

29. Wang Y, Zhang ZZ, Wu Y, Zhan J, He XH and Wang YL: Honokiol protects rat hearts against myocardial ischemia reperfusion injury by reducing oxidative stress and inflammation. Exp Ther Med 5: 315-319, 2013.

30. Su H, Yuan Y, Wang XM, Lau WB, Wang Y, Wang X, Gao E, Koch WJ and Ma XL: Inhibition of CTRP9, a novel and cardiac-abundantly expressed cell survival molecule, by $\mathrm{TNF} \alpha$-initiated oxidative signaling contributes to exacerbated cardiac injury in diabetic mice. Basic Res Cardiol 108: 315, 2013.

31. Wang Q, Cheng Y, Xue FS, Yuan YJ, Xiong J, Li RP, Liao X and Liu JH: Postconditioning with vagal stimulation attenuates local and systemic inflammatory responses to myocardial ischemia reperfusion injury in rats. Inflamm Res 61: 1273-1282, 2012.

32. Jin S and Dai CL: Attenuation of reperfusion-induced hepatocyte apoptosis is associated with reversed bcl-2/bax ratio in hemi-hepatic artery-preserved portal occlusion. J Surg Res 174: 298-304, 2012.

33. Yao Y, Huang C, Li ZF, Wang AY, Liu LY, Zhao XG, Luo Y, Ni L, Zhang WG and Song TS: Exogenous phosphatidylethanolamine induces apoptosis of human hepatoma HepG2 cells via the bcl-2/Bax pathway. World J Gastroenterol 15: 1751-1758, 2009.

34. Seelinger G, Merfort I and Schempp CM: Anti-oxidant, anti-inflammatory and anti-allergic activities of luteolin. Planta Med 74: 1667-1677, 2008. 